of the sun, a spot travels about $15^{\circ}$ per day, so that all spots between longitudes $-60^{\circ}$ and $+60^{\circ}$ are observable during two days or more; hence all spots occurring in this region are excluded from the count if their life exceeds two days, while spots in the remaining regions are observable for two days or less. Taking $-90^{\circ}$ as the limb of the sun which is rotating towards the earth, all spots classified as two day spots between about $-90^{\circ}$ and $-60^{\circ}$ may in fact have had any life up to about 16 days, and similarly all spots classified as two day spots between about $+60^{\circ}$ and $+90^{\circ}$ may have a life of from two days up to about 16 days, that is, in either zone half a revolution period of the sun plus rather more than two days. Actually the limits $60^{\circ}$ and $90^{\circ}$ must be replaced by somewhat smaller values to allow for the loss of spots by foreshortening, and in any event the foreshortening conquers at the limb where the number must finally fall off.

Thus we are to expect spurious maxima at about $\pm 75^{\circ}$ due to this selection, and this is precisely where Mr. Aiyar finds his extra maxima.

A more detailed numerical investigation will be described later.

J. A. Carrollu.

The University,

Aberdeen.

March 8.

${ }^{1}$ Mon. Not. R.A.S., 93, 150; 1932.

\section{Further Light on the Schneider Mediumship}

I HAVE read the review in NATURE of April 8 of Mr. Harry Price's "An Account of some Further Experiments with Rudi Schneider". To deal in detail with the charge of fraud brought by Mr. Price against Schneider in his report would take up more space than could be afforded in these columns. I have, however, been closely associated with all the experiments which have been made with this medium in England (April 1929 to December 1932), and I would ask all who are interested in these matters to withhold their judgment until a report has been published of further experiments held with this medium (October to December 1932). These further experiments were carried out in as scientific and impartial a manner as circumstances permitted and the results supplied strong indications that Schneider indeed possesses genuine 'supernormal faculties'.

In reply to the suggestion put forward in the review in question that the presence of a supposed accomplice invalidates Dr. E. Osty's report "Les Pouvoirs Inconnus de l'Esprit sur la Matière"-a report of careful experiments with the same medium, 1930-1931-it appears that the attempts of trickery in question were of a puerile order and in no way affected the main issue. The infra-red ray apparatus and objects subjected to telekinesis were completely separated from the medium and sitters by a clamped gauze net, 5 feet 6 inches high, and none of the attempts at trickery affected any phenomena on the far side of the net. Out of a total of ninety séances held by Dr. Osty, the suspect attended only fifteen, of which seven were blank and at none was telekinesis reported.

It should be noted that Mr. Price did not notify his Council or any of his invited sitters of (1) the existence of the incriminating photograph, (2) the friendly warning of Dr. Osty with regard to the suspect who, however, was allowed by Mr. Price to attend all the séances arranged by him.
It is hoped to carry out still further experiments with the same medium later this year, when various improvements will be adopted concerning both the technique of the séances and the scientific apparatus employed.

26A North Audley Street, London, W.1.

C. M. Hope.

Tracheal and Blood Gills in Aquatic Insect Larvæ

Among the larvæ of aquatic insects, two fairly well-defined types of gill-like structures are commonly found - 'tracheal gills' and 'blood gills'. The former term is applied to thin plates or filaments with a copious tracheal supply and only a very small blood cavity, structures which are typically developed in such insects as Ephemeroptera and Trichoptera. The term 'blood gill' is restricted to organs which have a spacious lumen but in which tracheæ are poorly developed or totally absent; the ventral and anal gills of Chironomus being a familiar example. The work of Fox $^{1}$ on Chironomus gave rise to doubt as to the respiratory function of blood gills in general, doubt which has been strengthened by the confirmatory work of Harnisch ${ }^{2}$, and in a recent series of papers Wigglesworth ${ }^{3}$ describes experiments upon the anal gills* of the larva of the yellow-fever mosquito (Aedes (Stegomyia) argentatus), from which he concludes that the main function of these structures is the absorption of water and that they are of little value as organs of respiration. Since in this species they are much larger than in the majority of allied forms, it is probably safe to assume that in the Culicidæ as a whole, anal gills are of little importance from the point of view of respiration : a conclusion which is confirmed by my own experiments on Culex spp.

In view of these results, it seems opportune to give a brief summary of experiments on blood gills and tracheal gills in other aquatic larvæ which I have carried out, a preliminary account of which is already in the press. The technique employed was similar to that described in a previous paper. In the case of the rectal blood gills of Trichoptera, it was not possible to detect any respiratory function, and similar results were obtained with the rectal gills of Simulium, Corethra, etc. One can therefore state that in no case has it been shown that the blood gills of aquatic larvæ serve any useful function in respiration. While there remains the possibility that these structures may come into play only within certain limits of oxygen tension, it may be said that the work of Harnisch gives no support to this hypothesis even in that form (Chironomus) in which it would appear most probable.

As might be expected, experiments with tracheal gills have yielded different results and have shown that these organs are undoubtedly active in respiration. But it has long been known that the larvæ of Agrionid dragon-flies can survive for a considerable period in the absence of caudal lamellæ and Cuenot ${ }^{6}$ showed that the tracheal gills of certain Ephemeroptera (Ephemera, Chloeon) can be removed without causing the death of the insect. In the Agrionids, the existence of general cutaneous respiration is easily demonstrated and my observations have shown that cutaneous respiration is also very prevalent among Ephemeroptera (Chloeon), Trichoptera (Limnophilus, Anabolia, Leptocera), Coleoptera (Gyrinus) and Neuroptera (Sialis), although in every case the tracheal gills are undoubtedly acting more 